\title{
Taxonomic Review of the Genus Echinochloa in Korea (I): Inferred from Sequences of cpDNA and nrDNA
}

\author{
Jeongran Lee*, Chang-Seok Kim, and In-Yong Lee \\ National Academy of Agricultural Science, Iseo 565-852, Korea
}

\begin{abstract}
The genus Echinochloa (L.) P. Beauv. comprised of approximately 30-40 species in the tropical and warm temperate regions of the world, including numerous interspecific and intraspecific types which make the genus difficult to identify. As an attempt to identify the species within the genus easier, the taxonomy of the genus Echinochloa, Poaceae in Korea was reviewed on the basis of sequencing data derived from nuclear ribosomal DNA internal transcribed spacer (ITS) and external transcribe spacer and chloroplast DNA trn L intron, trn L-F intergenic spacer and matK regions using a total of 46 accessions representing all the species in Korea. The results of maximum parsimony found separate lineage comprised of E. colona and E. frumentaceae which are not Korean species, but no resolution within Korean Echinochloa species, supporting the suggestion of Yamaguchi group that $E$. crus-galli, E. oryzoides, and E. esculenta should be considered to belong to the same species. However, the relationship between these three species and the other species, i.e. E. oryzicola should be better understood with more detail studies.
\end{abstract}

Key words: DNA sequences, Echinochloa, Phylogeny, Taxonomy

Received on June 3, 2014; Revised on July 30, 2014; Accepted on August 21, 2014

*Corresponding author: Phone) +82-63-238-3322, Fax) +82-63-238-3838; E-mail) kongsarang@korea.kr

(C) 2014 The Korean Society of Weed Science and The Turfgrass Society of Korea

This is an Open-Access article distributed under the terms of the Creative Commons Attribution Non-Commercial License \& \#160; (http://creativecommons.org/licenses/by-nc/3.0) which permits unrestricted noncommercial use, distribution, \& \#160; and reproduction in any medium, provided the original work is properly cited.

\section{Introduction}

The genus Echinochloa (L.) P. Beauv. includes 30-40 species in the tropical and warm temperate regions of the world. It is a difficult genus of numerous interspecific and intraspecific types. There is no reliable morphological character to distinguish them, resulting in poor taxonomic understanding of the genus (Clayton and Renvoize, 1999). Although the two species of Echinochoa, E. frumentacea Link and E. esculenta (A.Braun) H.Scholz, are grown as minor cereal crops in India, China and Japan, several species are aggressive colonizers of disturbed habitats and major noxious weeds in cultivated areas of the world (De Wet et al., 1983). Especially, E. crus-galli (L.) P. Beauv, E. colona (L.) Link and E. oryzicola (Vasinger) Vasinger are problematic weeds in many paddy fields of Eastern Asian countries. The two species, E. crus-galli and E. oryzicola are noxious weeds in Korean agricultural fields as well. Echinochloa crus-galli exhibits very diverse morphological and ecological forms and includes several varieties such as var. echinata (Willd.) A. Chev., var. praticola Ohwi, var. muticum (Sickenb.) Simps., and var. sieberiana (Asch. \& Schweinf.)
Chevalier. The two varieties, echinata and praticola, however, have been treated as either the synonyms of var. crus-galli or independent varieties depending on taxonomists (The Plant List, 2014). The wide morphological and ecological diversity may be related to the allohexaploidy of the species (Yabuno, 1983).

The scientific name of $E$. oryzicola has been controversial as E. phyllopogon (Stapf) Stapf ex Kossenko, E. crus-galli var. oryzicola (Vasinger) T. Koyama, tetraploid E. crus-galli var. oryzicola and E. oryzoides (Ard.) Fritsh (Yamaguchi et al., 2005). Tabacchi et al. (2006) and Michael (2007) have, however, treated $E$. oryzoides as a different species from $E$. oryzicola by drooping panicles at maturity, lower glumes with usually $1 / 4-2 / 5$ as long as the spikelets, awned lower lemmas, and the number of chromosomes, $2 n=54$, confirmed by Lee et al. (2013).

It was known that seven morphological taxa of the genus, $E$. crus-galli var. crus-galli, var. echinata, var. praticola, E. oryzicola, E. colona (L.) Link, E. glabrescens, and E. esculenta, are distributed throughout Korea and one more species, $E$. oryzoides, has been recently added (Lee et al., 2013). Although they provided the key to the genus Echinochloa of Korea, 
morphological identification is very difficult because interspecific and intraspecific variations are very often observed in the open fields.

The objective of this study was to identify the taxa of Echinochloa and review the treatment of E. crus-galli varieties echinata and praticola to var. crus-galli. We also aim to resolve the phylogenetic relationships among the Korean Echinochloa taxa using molecular methods.

\section{Materials and Methods}

\section{Sampling}

Forty-six accessions of the Echinochloa species and one accession of Setaria viridis were selected for sequencing. Most of the Korean Echinochloa species were collected by authors from August to September of 2011 throughout the South Korea and the foreign accessions were provided by National Plant Germplasm System, USDA-ARS, National Taiwan University Herbarium (TAI) and Prof. Qiang Sheng of Nanjing Agricultural University, China. Plant materials are presented in Table 1.

\section{DNA extraction and quantification}

Genomic DNA was isolated from the green leaves of plant materials using a Genomic DNA Isolation Kit (NucleoGen, Germany) according to the instructions provided. The isolated DNA concentration and relative purity were checked using a Nanodrop ND-1000 (Dupont Agricultural Genomic Laboratory) and adjusted to $25 \mathrm{ng} / \mu \mathrm{L}$ for PCR amplification.

Table 1. The 46 Echinochloa accessions used for sequencing analyses.

\begin{tabular}{|c|c|c|c|c|c|c|}
\hline ID & Taxa & Origin & ITS & ETS & trnL-F & matK \\
\hline E6 & E. oryzicola & & KF010176** & KF101250 & KF163558 & KF010213 \\
\hline $\mathrm{E} 7^{*}$ & E. oryzoides & India & KF010177 & KF101251 & KF163559 & KF010214 \\
\hline E8 & E. oryzoides & Masan, Gyeongsangnamdo & KC164281 & KF101252 & KC164291 & KC164269 \\
\hline $\mathrm{E}^{*}$ & E. crus-pavonis & Argentina & KC164274 & KF101253 & KF163560 & KC164262 \\
\hline E11 & E. crus-galli & Yeongjongdo, Inchon & KF010178 & KF101254 & KF163561 & KF010215 \\
\hline E13* & E. frumentacea & USA & KC164278 & KF101255 & KC164288 & KC164266 \\
\hline E25 & E. oryzicola & Hongcheon, Gangwondo & KC164279 & KF101256 & KC164289 & KC164267 \\
\hline E26 & E. oryzicola & Hongcheon, Gangwondo & KF010179 & KF101257 & KF163562 & KF010216 \\
\hline E27 & E. oryzicola & Hongcheon, Gangwondo & KF010180 & KF101258 & KF163563 & KF010217 \\
\hline E28 & E. oryzicola & Hongcheon, Gangwondo & KF010181 & KF101259 & KF163564 & KF010218 \\
\hline E31 & E. crus-galli & Naju, Jeollanamdo & KF010182 & KF101260 & KF163565 & KF010219 \\
\hline E38 & E. crusgalli var. echinata & Naju, Jeollanamdo & KF010183 & KF101261 & KF163566 & KF010220 \\
\hline E40 & E.crus-galli & Naju, Jeollanamdo & KF010184 & KF101262 & KF163567 & KF010221 \\
\hline E46 & E. oryzicola & Gyehwado, Jeollabukdo & KC164280 & KF101263 & KC164290 & KC164268 \\
\hline E53 & E. crusgalli var. echinata & Seosan, Choonchungnamdo & KF010185 & KF101264 & KF163568 & KF010222 \\
\hline E54 & E.crus-galli & Seosan, Choonchungnamdo & KF010186 & KF101265 & KF163569 & KF010223 \\
\hline E55 & E. oryzicola & Choonchon, Gangwondo & KF010187 & KF101266 & KF163570 & KF010224 \\
\hline E56 & E. crus-galli & Yeongjongdo, Inchon & KF010188 & KF101267 & KF163571 & KF010225 \\
\hline E58 & E. oryzicola & Gyehwado, Jeollabukdo & KC164272 & KF101268 & KC164284 & KC164260 \\
\hline E80 & E. esculenta & Jejusi, Jejudo & KC164277 & KF101269 & KC164287 & KC164265 \\
\hline E81 & E. crus-galli & Seogwiposi, Jejudo & KC164276 & KF101270 & KC164286 & KC164264 \\
\hline E88 & E. crus-galli var. praticola & Naju, Jeollanamdo & KF010189 & KF101271 & KF163572 & KF010226 \\
\hline E89 & E. crus-galli var. praticola & Naju, Jeollanamdo & KF010190 & KF101272 & KF163573 & KF010227 \\
\hline $\mathrm{E} 90^{*}$ & E. crus-galli & Phillipines & KF010191 & KF101273 & KF163574 & KF010228 \\
\hline E91* & E. colona & China & KC164275 & KF101274 & KF163575 & KC164263 \\
\hline E93* & E.crus-galli & China & KF010192 & KF101275 & KF163576 & KF010229 \\
\hline E95* & E.crus-galli & China & KF010193 & KF101276 & KF163577 & KF010230 \\
\hline E96* & E.crus-galli & China & KF010194 & KF101277 & KF163578 & KF010231 \\
\hline E99* & E. crus-galli var. austro-japonesis & China & KF010195 & KF101278 & KF163579 & KF010232 \\
\hline
\end{tabular}


Table 1. The 46 Echinochloa accessions used for sequencing analyses (continued).

\begin{tabular}{lllllll}
\hline E100 & E. oryzicola & China & KF010196 & KF101279 & KF163580 & KF010233 \\
E105 & E.crus-galli & Cheongsong, Gyeonsangbukdo & KF010197 & KF101280 & KF163581 & KF010234 \\
E109 & E.crus-galli & Gyeongju, Gyeonsangbukdo & KF010198 & KF101281 & KF163582 & KF010235 \\
E114 & E.crus-galli var. echinata & Busan & KF010199 & KF101282 & KF163583 & KF010236 \\
E115 & E.crus-galli var. echinata & Busan & KF010200 & KF101283 & KF163584 & KF010237 \\
E116 & E.crus-galli & Busan & KF010201 & KF101284 & KF163585 & KF010238 \\
E117 & E.crus-galli & Busan & KF010202 & KF101285 & KF163586 & KF010239 \\
E120 & E.crus-galli & Busan & KF010203 & KF101286 & KF163587 & KF010240 \\
E121 & E.crus-galli & Busan & KF010204 & KF101287 & KF163588 & KF010241 \\
E123 & E.crus-galli & Jecheon, Choongcheonbukdo & KF010205 & KF101288 & KF163589 & KF010242 \\
E125 & E. oryzicola & Gwangyang, Jeollanamdo & KF010206 & KF101289 & KF163590 & KF010243 \\
E130 & E.crus-galli var. praticola & Namhae, Gyeongsangnamdo & KF010207 & KF101290 & KF163591 & KF010244 \\
E132 & E.crus-galli var. echinata & Jangseong, Jeollanamdo & KF010208 & KF101291 & KF163592 & KF010245 \\
E133 & E.crus-galli & Sooncheon, Jeollanamdo & KF010209 & KF101292 & KF163593 & KF010246 \\
E137 & E.crus-galli var. praticola & Sancheong, Gyeongsangnamdo & KF010210 & KF101293 & KF163594 & KF010247 \\
E138 & E. oryzicola & Paju, Gyeonggido & KF010211 & KF101294 & KF163595 & KF010248 \\
E140 & E. oryzicola & Wonju, Gangwondo & KF010212 & KF101295 & KF163596 & KF010249 \\
\hline
\end{tabular}

${ }^{\star}$ Foreign origin

${ }^{\star *}$ Genbank accession number

\section{Sequencing and Phylogenetic analysis}

The cpDNA, matK and trnL intron and trnL-F intergenic spacer, and nrDNA ETS and ITS regions were PCR amplified using primers provided in Table 2. Details of PCR amplification reactions and purification were the same as described in Lee and Hymowitz (2001). DNA sequencing was conducted at the Genotech, Daejeon, Korea. The analyzed DNA sequences were aligned with Clustal W with manual editing and gaps were positioned to minimize nucleotide mismatches if necessary. Some ambiguously aligned sequences were not included in the phylogenetic analysis. Pairwise nucleotide differences of unambiguously aligned positions were determined using the distance matrix option in $\mathrm{PAUP}^{\star} 4.0 \mathrm{~b}$ 10 (Swofford, 1998). All gaps were treated as missing data.
Data sequences have been submitted to the National Center for Biotechnology information (NCBI) and obtained GenBank numbers.

Maximum parsimony analyses of ITS, ETS, trnL-F and matK were performed individually and in combination using PAUP $^{\star}$ 4.0b 10. A heuristic search was carried out with 100 random addition replicates and tree bisection-reconnection (TBR) branch swapping. The options with MULPARS, STEEPEST DESCENT, COLLAPSE, and ACCTRAN optimization were selected to search for the most parsimonious trees. Bootstrap analysis (Felsenstein, 1985) of 1000 replicates was performed using MEGA 5.2 (Tamura et al., 2011) with simple addition and TBR branch swapping options to evaluate the degree of support for each branch. The amount of

Table 2. Primers and reaction conditions used in this study.

\begin{tabular}{|c|c|c|c|c|}
\hline $\begin{array}{l}\text { Seqeuncing } \\
\text { regeions }\end{array}$ & Primers & Primer sequences & Annealing temperatures & References \\
\hline ITS & $\begin{array}{l}\text { ITS4 } \\
\text { ITS-Y5 }\end{array}$ & $\begin{array}{l}\text { TCCTCCGCTTATTGATATGC } \\
\text { TAGAGGAAGGAGAAGTCGTAACAA }\end{array}$ & 57 & $\begin{array}{l}\text { White et al. (1990) } \\
\text { Kita \& Ito (2000) }\end{array}$ \\
\hline ETS & $\begin{array}{l}\text { RETS4_F } \\
\text { 18S_R }\end{array}$ & $\begin{array}{l}\text { TGGCTACGCGAGCGCATGAG } \\
\text { AGACAAGCATATGACTACTGGCAGG }\end{array}$ & 55 & $\begin{array}{l}\text { Gillespie et al. (2010) } \\
\text { Starr et al. (2003) }\end{array}$ \\
\hline $\operatorname{trnL}-\mathrm{F}$ & $\begin{array}{l}\text { Trn-F } \\
\text { Trn-C }\end{array}$ & $\begin{array}{l}\text { ATTTGAACTGGTGACACGAG } \\
\text { CGAAATCGGTAGACGCTACG }\end{array}$ & 54 & $\begin{array}{l}\text { Taberlet et al. (1991) } \\
\prime \prime\end{array}$ \\
\hline matK & $\begin{array}{c}\operatorname{Trn} 3914 \mathrm{~F} \\
\text { P1 } \\
\text { W } \\
\operatorname{trnK}-2 \mathrm{R}\end{array}$ & $\begin{array}{l}\text { TACCCTATCCTATCCAT } \\
\text { AACTAGTCGGATGGAGTAG }\end{array}$ & 55-50 touch down & $\begin{array}{c}\text { Johnson / Soltis (1994) } \\
\text { Designed in this study } \\
\text { Hilu et al. (1999) } \\
\text { Kelly Steele (1991) }\end{array}$ \\
\hline
\end{tabular}


Table 3. Sequence characteristics of the ITS, ETS, ITS+ETS, trnLintron and trnL-F intergenic spacer region, matK and trnL$\mathrm{F}+$ mat $\mathrm{K}$ in 46 taxa of the Echinochloa. Outgroup, Setaria viridis, was not included for sequence characteristics.

\begin{tabular}{lccccccc}
\hline \hline Characteristics & ITS & ETS & ITS + ETS & trnL-F & matK & trnL-F + matK & All combined \\
\hline Length range (bp) & $585-589$ & $448-449$ & $1034-1038$ & $823-829$ & $2373-2376$ & $3196-3205$ & $4230-4241$ \\
Aligned length (bp) & 590 & 450 & 1040 & 857 & 2389 & 3244 & 4283 \\
Sequence divergence (\%) & $0-4.06$ & $0-3.45$ & $0-3.69$ & $0-0.49$ & $0-.0 .68$ & $0-0.6$ & $0-1.31$ \\
No. of excluded sites (\%) & 0 & 0 & 0 & $12(0.37)$ & 0 & 12 & $75(1.75)$ \\
No. of included sites (\%) & 590 & 450 & 1040 & $845(98.6)$ & 2387 & $3232(99.6)$ & $4208(98.3)$ \\
No. of indels & 5 & 1 & 6 & 9 & 5 & 14 & 20 \\
No. of variable sites & $105(17.8)$ & $94(20.89)$ & $199(19.13)$ & $44(5.2)$ & $83(3.48)$ & $127(3.93)$ & $364(8.65)$ \\
No. of informative sites (\%) & $31(5.25)$ & $76(16.89)$ & $150(14.42)$ & $40(4.73)$ & $20(0.84)$ & $24(0.74)$ & $75(1.78)$ \\
No. of autapomorphic sites (\%) & $74(12.54)$ & $18(4.0)$ & $49(4.71)$ & $4(0.47)$ & $63(2.64)$ & $103(3.19)$ & $289(6.87)$ \\
CI of parsimony informative site & 0.9310 & 0.9510 & 0.9276 & 1.0000 & 0.9655 & 0.9773 & 0.9331 \\
\hline
\end{tabular}

phylogenetic information in the parsimony analysis was estimated using the consistency index (Kluge and Farris, 1969) and retention index (Farris, 1989). Distance trees based on combined sequencing data were constructed using the neighbor-joining method (Saitou and Nei, 1987) using PAUP* 4.0b 10 (Swofford, 1998). The numbers of nucleotide substitutions (excluding gaps) were estimated using the twoparameter method of Kimura (1980).

\section{Results}

Forty-seven samples, examining for $m a t \mathrm{~K}, \operatorname{trn} \mathrm{L}$ intron and trnL-F intergenic spacer, ETS, and ITS sequence represent seven species of Korean and foreign origins and an allied species as the outgroup. Characteristics of aligned sequences are provided in Table 3.

\section{cpDNA sequence analyses}

The sequence lengths were 823-829 bp in trnL-F, 2373$2376 \mathrm{bp}$ in $m a t \mathrm{~K}$ and $3196-3205 \mathrm{bp}$ in $\operatorname{trn} \mathrm{L}-\mathrm{F}+$ matK. They were aligned into $857 \mathrm{bp}, 2389 \mathrm{bp}$ and $3244 \mathrm{bp}$, respectively, of which $44 \mathrm{bp}, 83 \mathrm{bp}$, and $127 \mathrm{bp}$ were variable and $4 \mathrm{bp}$ (0.47\%), 63 bp (2.64\%), and 103 bp (3.19\%) were parsimony informative. For the ingroup, direct pairwise distance ranged from identity to $0.49 \%, 0.68 \%$, and $0.6 \%$ in trnL-F, mat $\mathrm{K}$ and trn $\mathrm{L}-\mathrm{F}+$ mat $\mathrm{K}$ between $E$. colona and several samples, respectively. The heuristic search identified 16,383 equally parsimonious trees of 132 steps with consistency indices of 0.8966 (excluding uninformative characters) and 0.9773 (including uninformative characters) and a retention index of 0.9845 using trn $\mathrm{L}-\mathrm{F}+$ mat $\mathrm{K}$. Bootstrap values ranged from 54 to $100 \%$.

\section{nrDNA sequence analyses}

The lengths of the ITS, ETS, and ITS + ETS were 585-589 bp, 448-449 bp, and 1034-1038 bp, then aligned into 590 bp, $450 \mathrm{bp}$, and $1040 \mathrm{bp}$, respectively. The number of variable sites was $105 \mathrm{bp}, 94 \mathrm{bp}$, and $199 \mathrm{bp}$, of which $31 \mathrm{bp}$ (5.25\%), 76 bp (16.89\%), and 150 bp (14.42\%) were parsimony informative sites. Direct pairwise distance ranged from identity to $4.06 \%$, $3.45 \%$, and $3.69 \%$ between E. colona and E. crus-galli, respectively. Parsimony analysis of 47 ITS + ETS using equally weighted character states resulted in 30,300 parsimonious trees. The trees have a length of 221 steps, consistency indices of 0.7647 (excluding uninformative characters) and 0.9276 (including uninformative characters) and a retention index of 0.8865 . Bootstrap values ranged from 63 to $100 \%$.

\section{Combined cpDNA and nrDNA analysis}

The length of all combined data were 4,230-4,231 bp, then aligned into 4,283 bp, of which $364 \mathrm{bp}$ were variable and $75 \mathrm{bp}$ were parsimony informative. Maximum parsimony analysis produced 7,693,100 trees of 478 steps. Consistency indices of 0.7117 (excluding uninformative characters) and 0.9128 (including uninformative characters) and a retention index of 0.8865. Bootstrap values ranged from 65 to $100 \%$. Direct pairwise distance ranged from identity to $1.31 \%$ between the clade of E. colona and E. frumentacea and E. crus-pavonis.

\section{Phylogenetic resolution}

The strict consensus trees obtained from cpDNA and nrDNA are shown in Fig. 1. The genus Echinochloa was monophyletic in both trees. The Echinochloa was consisted of two main lineages in both trees, although the clustering was different. One clade (I) was consisted of E. crus-pavonis, E. crus-galli, E. escuenta and E. oryzoides and the other clade (II) was consisted of the rest of the examining taxa, $E$. frumentacea, E. colona, E. oryzicola, and E. crus-galli, in the cpDNA tree. On the other hand, E. frumentacea and its progenitor E. colona were located at the basal to all other taxa in the nuclear DNA tree. Echinochloa crus-pavonis, clustered 


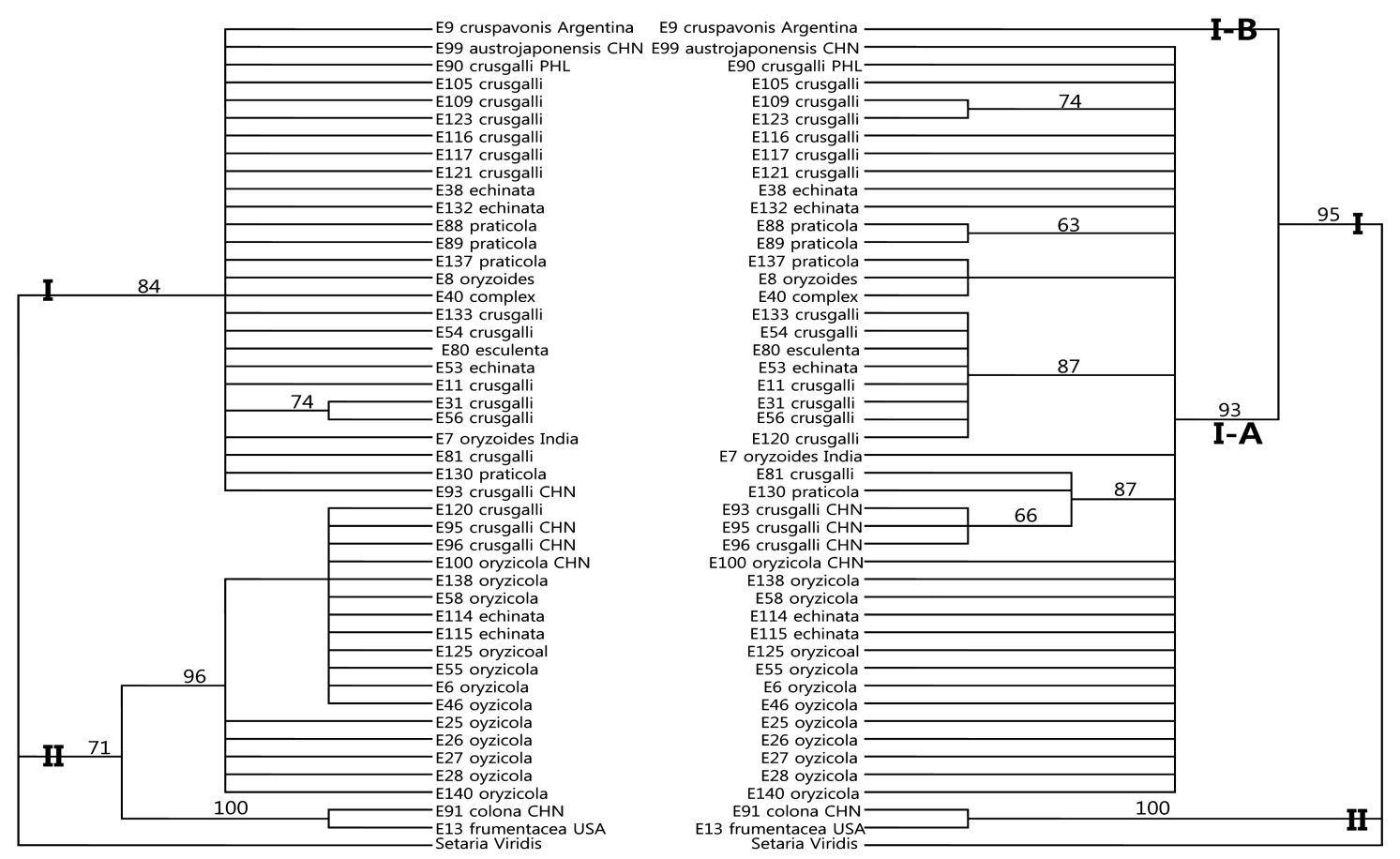

Fig. 1. Maximum parsimony tress derived from chloroplast DNA trnL intron, trnL-F intergenic spacer and matK and nuclear ribosomal DNA internal transcribed spacer (ITS) and external transcribe spacer regions using a total of 46 accessions. Left is a strict consensus of 16,383 maximum parsimonious trees based on cpDNA (tree length $=132$, Consistency index $(\mathrm{CI})=0.9773$, and Retention index $(\mathrm{RI})=0.9845)$. Right is a strict consensus of 30,300 maximum parsimonious trees based on nrDNA (Tree length $=221$, Consistency index $(\mathrm{CI})=0.9276$, and Retention index $(\mathrm{RI})=0.8865)$. The numbers above the branches indicate a bootstrap value of $>50 \%$.

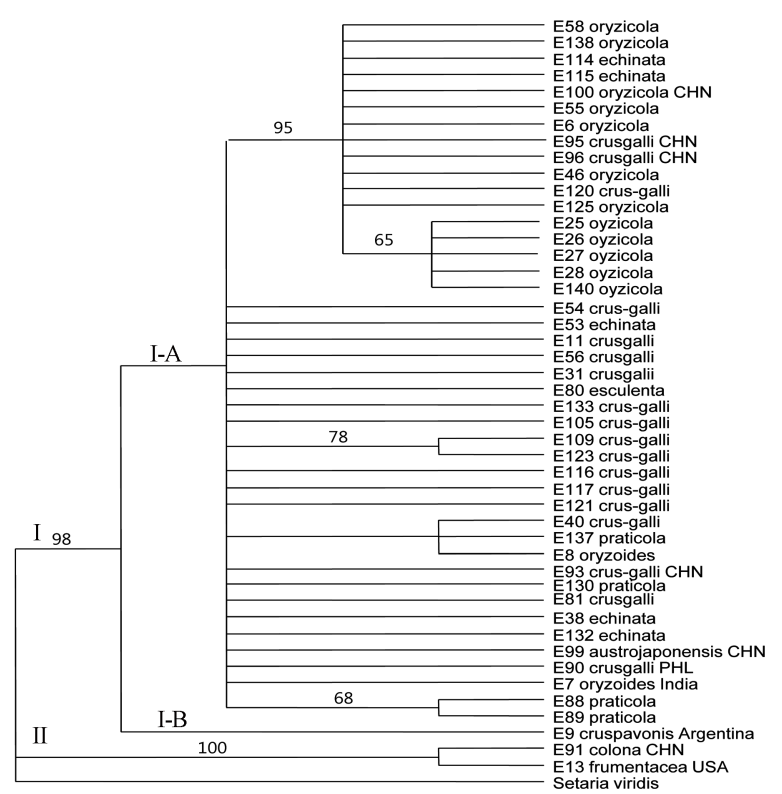

Fig. 2. A strict consensus of 7,693,100 maximum parsimonious trees derived from all combined data set. Tree length is 478 steps. Consistency indices of 0.7117 (excluding uninformative characters) and 0.9128 (including uninformative characters) and a retention index of 0.8865 . The numbers above the branches indicate a bootstrap value of $>50 \%$. Bootstrap values ranged from 65 to $100 \%$. with E. crus-galli, E. escuenta and E. oryzoides in the strict consensus tree based on cpDNA solely consisted of a subclade in clade I in the tree based on nrDNA.

The strict consensus tree of all combined markers showed the similar topology to that derived from nrDNA (Fig. 2). It was consisted of two lineages, one was a clade of $E$. frumentacea and E. colona (II) and the other lineage was consisted of the others (I). The large clade (I) comprising the E. crus-pavonis, E. oryzicola, E. crus-galli, E. oryzoides, and E. esculenta was supported by a high bootstrap, 98\%. Echinochloa crus-pavonis solely consisted a subclade (I-B) within the clade I. The subclade I-A was comprised of E. oryzicola, E. crus-galli, E. oryzoides, and E. esculenta which are treated as crus-galli complex by Aoki and Yamaguchi (2008). Echinochloa oryzicola with a few accessions of E. crus-galli, however, consist a independent subclade with a high bootstrap value of $95 \%$, within the clade I-A. Intersetingly, several accessions of $E$. oryzicola (i.e; E25, 26, 27, 28, and 140) formed a lineage in the combined analysis while they were not monophyletic in both cpDNA and ITS sequences-derived analyses.

All the distance trees (not shown) inferred from the neighbor-joining analyses of each cpDNA, nrDNA, and all combined regions were congruent with the maximally parsimonious trees. There was no clustering difference at all between the neighbor-joining and parsimonious trees. 


\section{Discussion}

Although genus Echinochloa has received attention among agronomists due to its properties of the noxious weeds in many agricultural fields, overall comprehensive taxonomic study is still lacking. As an ongoing effort to determine the extent of morphological and phylogenetic relationships among Echinochloa species in Korea, we produced phylogeny of Echinochloa in Korea based on cpDNA and nrDNA sequences. Due to low levels of DNA sequence variations among species in both loci, the phylogenetic relationships were not fully resolved among closely related species.

The results of phylogenetic analyses using cpDNA and nrDNA sequences showed slightly different relationships with positions of E. crus-pavonis and a lineage of E. colona and $E$. frumentacea. Echinochloa crus-pavonis coming from Argentina was clustered with E. crus-galli, E. escuenta, and E. oryzoides in one of main clades of cpDNA strict consensus tree whereas solely consisted a subclade within clade I in nrDNA strict consensus tree. This is not congruent with the result of the study conducted by Yamaguchi et al. (2005) which included Nigerian diploid. Nigerian Echinochloa crus-pavonis was consisted of the sole clade in the strict consensus tree constructed using non-coding region sequences of $\operatorname{trn} \mathrm{T}-\mathrm{L}-\mathrm{F}$ of cpDNA. Argentinian E. crus-pavonis, however, was nested within the crus-galli complex in cpDNA trees (Aoki and Yamaguchi, 2008), which was congruent with the previous results. Aoki and Yamaguchi (2008) supposed that Echinochloa crus-pavonis described as a South American representative species (Michael, 2007) was clustered with the other South American E. crus-galli, implying a genetic difference between the American and Eurasian E. crus-galli. However, it may be reasonable to infer that this clustering was more related to phylogeographic relationships than to a genetic difference suggesting their different evolutionary process. More detailed phylogeographic stuty of E. crus-pavonis and E. crus-galli including extensive sampling from the American countries will help reveal the relationships.

Independent lineage of E. colona and E. frumentacea was strongly supported with $100 \%$ bootstrap in both trees. Echinochloa frumentacea is annually cultivated mostly in India and Central Africa. It is known to have been domesticated recently from E. colona (Clayton and Renvoize, 1999). Echinochloa colona is an annual weed widely distributed throughout the subtropical and tropical regions of Asia, Africa, and America. It is a hexaploid with $2 \mathrm{n}=6 \mathrm{x}=54$, but differs from E. crus-galli in genomic constitution (Yabuno, 1966, 1983). The close phylogenetic relationship between $E$. colona and E. frumentacea was also supported by previous studies (Yamaguchi et al., 2005; Aoki and Yamaguchi, 2008). Among E. oryzicola, E. crus-galli complex, E. crus-pavonis, and a clade of E. colona-frumentacea, the phylogenetic relationship was not resolved enough using cpDNA non-coding region sequences of $\operatorname{trn} \mathrm{T}-\mathrm{L}-\mathrm{F}$ in the study of Yamaguchi et al. (2005). However, a clade of E. colona - frumentacea was a basal group in both the cpDNA and nrDNA trees of Aoki and Yamaguchis study (2008) and in the nrDNA tree of this study. Interestingly, a clade of E. colona - frumentacea showed a close relationship with E. oryzicola clade with high bootstrap, $71 \%$ in the cpDNA tree of our study. This result may indicate that $E$. frumentacea and E. colona share the same maternal genetic background with E. oryzicola $(2 \mathrm{n}=4 \mathrm{x}=36)$, but not with crus-galli complex, when we consider the hypothesis that $E$. frumentacea and $E$. colona does not share the same genomes with $E$. esculenta and E. crus-galli (Yabuno, 1966).

It has been known that three botanical varieties of Echinochloa crus-galli, var. crus-galli, echinata and praticola are distributed in Korea. However, taxonomic treatment of these botanical varieties are not recognized as the distinct taxa by taxonomists who has a broad view of the species due to continuous morphological variations. Echinochloa crus-galli is allohexaploid (6X) and known to be composed of paternal donor of E. oryzicola and unknown maternal diploid (Aoki and Yamaguchi, 2008). Echinochloa oryzoides, distributed in Korea, China, Japan and North America and also hexaploid with $2 \mathrm{n}=54$, is known to share the same genome with $E$. crusgalli (Yabuno, 1984). Echinochloa esculenta, cultivated mostly in temperate regions in Korea, China, and Japan, is also hexaploid with a chromosome number of $2 n=6 x=54$. This species is known to have been domesticated from $E$. crus-galli (Yabuno 1966). Phylogenetic relationships among Korean Echinochloa; i.e. E. crus-galli including var. crus-galli, echinata and praticola, E. oryzicola, E. esculenta, and E. oryzoides, were remained poorly resolved in both analyses due to very low sequence variation with only 32 nucleotide substitutions out of 4,284 sequences. The average pairwise-distance values among Korean Echinochloa were $0.2 \%$ for ETS, matK, and $\operatorname{trn} \mathrm{L}-\mathrm{F}$ and $0.4 \%$ for ITS. One difference between the cpDNA and nrDNA trees is an independent clustering of E. oryzicola with high bootstrap, 96\%, in the cpDNA tree, but no relationship resolved in the nrDNA tree. Especially, relationship between E. oryzoides, E. esculenta, and E. crus-galli which are morphologically diverse, could not be discerned in this study due to limited resolutions in cpDNA and nrDNA sequences. These three species also showed the same sequences in the trnT-L-F coding regions using East Asian accessions in a molecular phylogenetic study of wild and cultivated Echinochloa conducted by Yamaguchi et al. (2005). Yamaguchi group supposed that these three species, called as a crus-galli complex, be considered to belong to the same species with more diverse studies including Isozyme analysis (Nakayama et al., 1999) and polymerase chain reaction-restiction fragment length polymorphism (PCR-RFLP) technique (Yasuda et al., 2002). The results of our study support their suggestion, 
especially in Korean Echinochloa.

\section{Acknowledgement}

This research was supported by a project from the Cooperative Research Program for Agricultural Science \& Technology Development (Project No. PJ008548) of the RDA.

\section{References}

Aoki, D. and Yamaguchi, H. 2008. Genetic relationship between Echinochloa crus-galli and Echinochloa oryzicola accessions inferred from internal transcribed spacer and chloroplast DNA sequences. Weed Biol. Manage. 8:233-242.

Clayton, W.D. and Renvoize, S.A. 1999. Genera Graminum, Grasses of the World. Royal Botanic Gardens, Kew, London, England, UK. pp. 280-281.

De Wet, J.M.J., Rao, K.E.P., Mengesha, M.H. and Brink, D.E. 1983. Domestication of sawa millet (Echinochloa colona). Econ. Bot. 37:283-291.

Farris, J.S. 1989. The retention index and homoplasy excess. Syst. Zoo. 38:406-407.

Felsenstein, J. 1985. Confidence limits on phylogenies: an approach using the bootstrap. Evolution. 39(4):783-791.

Kimura, M. 1980. A simple method for estimating evolutionary rates of base substitution through comparative studies of nucleotide sequences. J. Mol. Evol. 16:111-120.

Kluge, A.G. and Farris, J.S. 1969. Quantitative phyletics and evolution of anurans. Syst. Zoo. 18:1-32.

Lee, J. and Hymowitz, T. 2001. A molecular phylogenetic study of the subtribe Glycininae (Leguminosae) derived from the chloroplast DNA rps16 intron sequences. Am. J. Bot. 88:2064-2073.

Lee, J., Kim, C.-S. and Lee, I.-Y. 2013. Identification of Echinochloa oryzicola (Vasinger) Vasinger and E. oryzoides (Ard.) Fritsch in Korea. Korean J. Pla. Tax. 43:56-62. (In Korean)

Michael, P.W. 2007. Echinochloa P. Beauv. . In: Barkworth, M.E.,
Capels, K.M., Long, S. and Piep, M.B. (Eds.), Flora of North America, North of Mexico. Oxford University Press, New York, USA. pp. 390-403.

Nakayama, Y., Umemoto, S. and Yamaguchi, H. 1999. Identification of polyploid groups in the genus Echinochloa by isozyme analysis. J. Weed Sci. Tech. 44:205-217.

Saitou, N. and Nei, M. 1987. The neighbor-joining method: a new method for reconstructing evolutionary trees. Mol. Biol. Evol. 4(4):406-425.

Swofford, D.L. 1998. Phylogenetic analysis using parsimony, v. 4.01 beta. Sinauer, Sunderland, MA, USA.

Tabacchi, M., Mantegazza, R., Spada, A. and Ferrero, A. 2006. Morphological traits and molecular markers for classification of Echinochloa Species from Italian rice fields. Weed Sci. 54(6):1086-1093.

Tamura, K., Peterson, D., Peterson, N., Stecher, G., Nei, M., et al. 2011. MEGA5: Molecular evolutionary genetics analysis using maximum likelihood, evolutionary distance, and maximum parsimony methods. Mol. Biol. Evol. 28(10):2731-2739.

The Plant List. 2014. Version 1. http://www.theplantlist.org/. (Accessed on May 1, 2014).

Yabuno, T. 1966. Biosystematic study of the genus Echinochloa. Jap. J. Bot. 19:277-323.

Yabuno, T. 1983. Biology of Echinochloa Species International Rice Research Institute. International Weed Science Society, Los Banjos, the Philippines.

Yabuno, T. 1984. A biosystematic study on Echinochloa oryzoides (Ard.) Fritsch. Cytologia. 49:673-678.

Yamaguchi, H., Utano, A., Yasuda, K., Yano, A. and Soejima, A. 2005. A molecular phylogeny of wild and cultivated Echinochloa in East Asia inferred from non-coding region sequences of trnT-L-F. Weed Biol. Manag. 5:210-218.

Yasuda, K., Yano, A., Nakayama, Y. and Yamaguchi, H. 2002. Molecular identification of Echinochloa oryzicola Vasing. and E. crus-galli (L.) Beauv. using a polymerase chain reaction-restriction fragment length polymorphism technique. Weed Biol. Manag. 2(1):11-17. 